\title{
Experimental behavior of masonry wall-to-timber elements connections strengthened with injection anchors
}

\author{
Susana Moreira ${ }^{1}$, Luís F. Ramos ${ }^{2}$, Daniel V. Oliveira ${ }^{3}$, Paulo B. Lourenço ${ }^{4}$ \\ ISISE, Department of Civil Engineering, University of Minho, Guimarães, Portugal
}

${ }^{1} \mathrm{PhD}$ candidate, ISISE, Dep. of Civil Engineering, University of Minho, Campos de Azurém, 4800-058

Guimarães, Portugal. Phone: +351 253517 215, E-mail: su.moreira.pt@gmail.com (corresponding author)

${ }^{2}$ Assistant Professor, ISISE, Dep. of Civil Engineering, University of Minho, Campos de Azurém, 4800-058 Guimarães, Portugal. Phone: +351 253510 200, E-mail: 1ramos@ civil.uminho.pt

${ }^{3}$ Associate Professor, ISISE, Dep. of Civil Engineering, University of Minho, Campos de Azurém, 4800-058 Guimarães, Portugal. Phone: +351 253510 247, E-mail: danvco@civil.uminho.pt

${ }^{4}$ Full Professor, ISISE, Dep. of Civil Engineering, University of Minho, Campos de Azurém, 4800-058

Guimarães, Portugal. Phone: +351 253510 209, E-mail: pbl@civil.uminho.pt 


\begin{abstract}
Out-of-plane failure mechanisms observed in stone masonry buildings subjected to seismic action are often a direct result of poor connections between structural elements. During a seismic event these weak connections become incapable of assuring proper load transmission. Therefore, the need to prevent these phenomena is of critical importance in understanding the behavior of unstrengthened masonry buildings along with the necessity of developing effective strengthening solutions. This paper presents injection anchors as a viable option to improve anchorage between masonry and timber elements on historical buildings, as for example wall-to-timber framed wall or wall-to-timber diaphragm connections. The experimental campaign consisted of quasi-static monotonic and cyclic pullout tests performed on real scale specimens, representative of wall-to-timber framed wall connections found in late $19^{\text {th }}$ century buildings of downtown Lisbon, Portugal. Combined cone-bond failure was obtained in all 7 tests. Boundary conditions of the specimens greatly affected the results in terms of maximum pullout force, dissipated energy, and strength degradation. Displacement ductility of the strengthened connections is high. The force-displacement curves clearly pointed out the influence on the results of the wall's compressive stress state and the contribution of friction in the grout/masonry interface.
\end{abstract}

Keywords: wall-to-timber elements connection, injection anchor, cyclic pullout test, seismic retrofit, ductility 


\section{INTRODUCTION}

Since the late 1970s, several seismic tests have been carried out to understand the dynamic behavior of unreinforced masonry buildings [1;2]. A limited number of experimental campaigns have also been performed to investigate various strengthening techniques [3]. However, little research has been carried out in the past decades to characterize the behavior of connections between masonry walls and timber walls or floors [4; 5]. Postearthquake surveys of recent events - e.g. Azores 1998, L'Aquila 2009, and Christchurch 2011 — show that outof-plane collapse failures are the most common failure mechanisms in masonry buildings [6]. Although being a local mechanism, it can cause irreparable damage to culturally significant buildings or even compromise the overall stability of a structure. The absence of appropriate structural connections is known to be one of the main factors contributing to the activation of this type of failure mechanism [6]. Thus, there is a need to understand the unstrengthened behavior of these connections so that the characteristics of a strengthening solution can be determined to prevent the formation of out-of-plane mechanisms.

In spite of the fact that it provides a contribution to the behavior of steel anchors in traditional stone masonry walls, this study focuses on masonry wall to timber framed wall connections, specifically those found in buildings constructed after the 1755 earthquake that severely damaged the city of Lisbon, Portugal. From the immediate reconstruction period until 1930, several types of masonry and timber buildings were erected. The quality of materials and construction techniques decreased considerably over time, declining in quality from the so-called 'Pombalino' buildings to the 'Gaioleiro' buildings $[7 ; 8]$.

Initially, the so-called 'Pombalino' buildings had half-timbered walls that were part of a flexible three-dimensional timber frame (called 'gaiola' or 'cage'), which was an engineering innovation designed to decrease seismic vulnerability [1]. The timber frame of the half-timbered walls — consisting of vertical, horizontal, and diagonal members in a St. Andrews cross pattern — increased resistance to horizontal loading and effectively dissipated energy. The frames were completed with brick or rubble masonry infill, which increased their mass. For the 'Gaioleiro' buildings, the half-timbered walls disappeared giving place to simplified timber framed walls or even just lath and plaster walls.

The external and party walls of the first 'Pombalino' buildings were of limestone rubble masonry with constant thickness between $0.50 \mathrm{~m}$ and $0.70 \mathrm{~m}$, while the ones from the 'Gaioleiro' buildings varied in thickness along the height of the building. These walls were built stone by stone, arranged in the best way possible with all voids filled 
with mortar. The mortar was a mixture of air lime and sand, usually in the proportion of 1:2, but other ratios like $1: 2.5,1: 3$ or $5: 9$ were used as well [9]. Existing historic material descriptions specify that the sand should be of good quality and from a specific place of pine trees, probably referring to the Leiria region, in the central part of Portugal. They also prescribed that the stone should be soft (like limestone), of good quality, and should come from Monsanto or Sacavém, as described in records found in the Municipal Archive of Lisbon. Several authors suggest that the compressive strength of irregular masonry with a poor mortar, with the ratios suggested before, should be in the ranges from $0.8 \mathrm{MPa}$ to $1.5 \mathrm{MPa}$ [10] or $0.5 \mathrm{MPa}$ to $1.0 \mathrm{MPa}$ [8]. The elastic modulus should be in the range from $700 \mathrm{MPa}$ to $900 \mathrm{MPa}[10]$.

Different types of wall-to-timber framed wall connections have been described in literature, as shown in Fig. 1. The connection varies according to the amount of timber elements inside the wall and their anchorage length, relying mainly on friction to ensure the connection. Connection types C1 to C5 are common in 'Pombalino' and Late 'Pombalino' buildings, where the three-dimensional timber cage was the main concern. In 'Gaioleiro' buildings, where timber framed walls (or a degraded version) still exist, connection type C6 is commonly found. In this type of connection, the timber framed wall leans against the masonry wall, leaving only the floor joists to maintain the continuity of force distribution [11].

Silva [12] describes some in situ pullout tests carried out on connections from type C1 to C5 in a 'Pombalino' building. No information is provided about anchorage length, the story where the connection was found, or any other significant details. However, the pullout horizontal forces obtained in the tests ranged from $1.5 \mathrm{kN}$ to $6 \mathrm{kN}$. Such a limited capacity contrasts with the resistant capacity of the masonry and half-timbered walls, suggesting the necessity of strengthening solutions to improve load transfer between both structural elements. This is critical since this type of connection connects elements with very different stiffnesses, strengths, and therefore behaviors. The masonry wall, with a much larger stiffness and mass, dictates the out-of-plane behavior. Thus, it is necessary to anchor the flexible timber frame to the masonry in order to expect effective resistance to out-of-plan failures during a seismic event.

In the design and analysis of masonry structures, connections are usually considered to describe one of the two extremes conditions of rigidity: fully constrained (fixed) or pinned. Elements can be mechanically connected in so many ways that often these simplifications do not reflect the true structural response. Recent studies conducted in 
'Pombalino' and 'Gaioleiro' buildings have shown that the consideration of these two extremes has a significant impact on the numerical results and, consequently, on the assessment of buildings' seismic vulnerability [5; 13].

Most strengthening solutions for connections between timber elements and masonry walls are force designed and rely on anchoring systems like tie rods with anchor plates bolted to the timber elements by means of steel angles, as shown in Fig. 2a [14]. Pinho [8] and Mascarenhas [7] refer the use of similar anchor systems in 'Pombalino' buildings on connections between masonry walls and floor joists. Another possible anchor system is injection anchors, which have been applied in masonry since the 1920s in Germany [15]. The installation of injection anchors is advantageous in comparison to tie rods and anchor plates since injection anchors require access from only one side of a wall, which facilitates interventions on façade and party walls.

The present study focuses on the solution proposed by Silva [12], which consists of a pair of injection anchors placed in pre-drilled holes in a masonry wall. The timber framed wall goes between the parallel injection anchors so that a symmetrical behavior can be explored (see Fig. 2b). The injection anchor itself is a steel rod inside a woven polyester based tubular sleeve, provided by the company $\mathrm{Cintec}^{\circledR}$. It is placed in a pre-drilled hole and injected, under low pressure, with a cementitious grout. The sleeve can expand to suit the diameter of the borehole, which can vary according to the steel bar diameter, and control the flow of grout into voids. The distance between anchors can vary according to the thickness of the half-timbered wall and the steel gusset plates. These plates are bolted to both sides of the half-timbered wall, usually at the intersection of the different timber elements of the cross (vertical, horizontal and diagonal), so that they work as a double shear connection. This strengthening application tries to respect the concept of "minimum intervention" required for historical interventions. Although focus is given here to the connection between timber framed walls and masonry walls, the strengthening solution analyzed in this work can also be extended to other types of connections found in masonry constructions, namely timber floors to masonry walls.

Load transfer mechanisms for injection (bonded) anchors involve mechanical interlocking between injection anchor and masonry substrate, local mechanical interlocking between injection mortar and voids, and bond and friction between sleeve-grout and surface of the drilled hole[16; 17]. The existence of a washer at the end of the steel rod prevents the failure at the rod/grout interface. Two other possible failure modes are masonry cone breakout and combined cone-bond failure [17], as shown in Fig. 3. The injection anchor can also fail by yielding 
of the steel rod, which can be controlled by properly choosing the steel grade and diameter. These failure modes are confirmed extensively in literature [18-21].

The experimental campaign on the injection anchors took place in the Structural Laboratory of University of Minho. Main outcomes included failure modes, maximum pullout force, force-displacement curves, and energy dissipation. These data clarifies the response of strengthened connections to cyclic actions and allows for future analytical development, and design recommendations.

\section{PULLOUT TEST SET-UP}

\subsection{Specimens and apparatus}

Two masonry walls with a rectangular shape and dimensions of $2.0 \times 0.4 \times 1.6 \mathrm{~m}^{3}$ were hand built by professional masons, without the use of any formwork. The irregular stone masonry walls were built with lime stones of different dimensions, ranging from a minimum unit dimension of $0.1 \mathrm{~m}$ to a maximum of $0.2 \mathrm{~m}$, with joints of maximum dimension of $0.05 \mathrm{~m}$ (see Fig. 4). The denomination used was WT.40.I.1 and WT.40.I.2; where WT stands for wall-to-timber framed wall, 40 represents the thickness of the wall in $\mathrm{cm}$, I refers to the injection anchors, and 1 or 2 is a reference to the wall number. Four pairs of injection anchors were installed in each wall, which allowed for eight tests to be carried out on each wall sample. The tests were referenced using letters: A and B to the bottom of the wall, C and D to the top of the wall (see Fig. 5).

Geometry, constructive details, and expected failure modes of the anchor system were established through the consideration of existent literature $[21 ; 22]$. Other aspects like laboratory conditions and availability of resources also were taken into consideration. As presented previously, connection type C6 (see Fig. 1) can be considered the most unfavorable because the lack of timber elements embedded in the masonry wall does not allow the connection to take advantage of friction. Considering this, and the fact that the double shear connection between steel gusset plates and timber elements can be properly designed using for instance EC5 [23], it was decided that the specimens would include only the masonry panel and the anchor system, as shown in Fig. $\mathbf{5}$.

The diameter of the steel ties in each wall was different: for the WT.40.I.1 a $\$ 20 \mathrm{~mm}$ tie was used and for the WT.40.I.2 a $\phi 16 \mathrm{~mm}$ tie was used. Despite the different tie diameter, the boreholes were uniformly drilled with a $\phi 50 \mathrm{~mm}$ diameter. By keeping the same borehole diameter for two different tie's diameter, one may conclude on the influence of the latter on the results. 
Both walls were built with a thickness of $0.40 \mathrm{~m}$. This wall thickness is representative of a $4^{\text {th }}$ floor of a 'Gaioleiro' building. Wall thickness had impact on the embedment length of the anchor, and consequently, on the force necessary to form the masonry cone failure. Therefore, by choosing a smaller wall thickness a conservative approach could be assumed. Interference between tests had to be avoided, so length and height of the wall, $2.0 \mathrm{~m}$ and $1.6 \mathrm{~m}$ respectively, were established considering a $90^{\circ}$ opening angle at the end of each anchor and an anchorage length $\left(l_{b}\right)$ of $0.35 \mathrm{~m}$. This embedment length corresponds to the thickness of the wall minus $0.05 \mathrm{~m}$, in order to allow some geometrical tolerance in real case study applications. The distance between parallel injection anchors was calculated considering a $0.12 \mathrm{~m}$ thick timber framed wall in between plus the dimensions of the steel gusset, giving approximately a total of $0.30 \mathrm{~m}$.

After 28 days following construction, the walls were loaded with a vertical compressive stress of 0.2 MPa to simulate the quasi-permanent stress state of a $4^{\text {th }}$ floor wall. The anchoring system was installed only after the walls were loaded. This consideration was critical in properly representing the installation of these anchors in the field. The permanent compression of real walls has a direct impact on the stress state of the anchors when they are installed and on the entire process. The holes were cored at room temperature of $20^{\circ} \mathrm{C}$, with a diamond tipped blade, and afterwards were cleaned with compressed air and a nylon bristle brush.

The loads considered for the quasi-permanent combination were self-weights of various architectural details, balconies, floors, roof components, and other imposed loads for residential areas as recommended in EC1 [24]. This was implemented in the test setup, by placing two HE200B steel profiles on top of the wall to distribute the load provided by four hydraulic cylinders compressed against a reaction slab (see Fig. 6a). The distributed vertical load was kept constant during the entire test using a manual control to adjust the level of pressure. Due to the imperfections of the steel profiles and the irregularity of the masonry, the masonry walls were leveled with mortar and a neoprene layer was placed between the two of them.

It was possible to develop a self-balanced apparatus capable of redirecting the pullout force back to the specimen, as shown in Fig. 6b. The pullout load was applied on each pair of anchors at the same time, perpendicular to the wall, using a metallic clamp. The clamp was specially designed for this connection, being rigidly connected to the anchors and hinged on the end connected to the actuator. In order to perform cyclic tests the set-up had to be anchored to the masonry wall by using 4 steel bars through the wall and anchor plates. The bars all worked in the elastic range during the test. 
Fig. 7a shows the displacements needed to be measured in order to characterize the loaded end slip $\left(s_{L}\right)$ and the total slip $\left(s_{T}\right)$. The loaded end slip represents the behavior of the interface grout/masonry, defined as the relative displacement between the loaded end of the anchors (average of displacements measured at points 6 and 8 of Fig. 7b) and the front face of the wall (average of displacements measured at points from 2 to 12 , except for 6 and 8 , of Fig. 7, which are inside the expected projected area of the cone). The total displacement is the relative displacement between the loaded end of the anchor and the back face of the wall measured outside the potential cone failure area. Total displacement is related with the global performance, meaning that it includes contributions from the grout/masonry interface and the masonry cone failure.

A total of 16 Linear Variable Differential Transducers (LVDTs) were distributed on the specimen (see Fig. 7b), of which 12 were placed on the wall (11 on the front of the wall and 1 on the back) to monitor the out-of-plane displacements, as presented in Fig. 8. The LVDTs were placed exclusively on stones to avoid premature detachment, as this is known to happen to mortar. Their distribution on the wall followed a quadrangular grid of $150 \mathrm{~mm}$ around the two parallel anchors and they were specially concentrated around the anchors. A set of 4 LVDTs were also placed on the loaded and free ends of the injection anchors. The LVDTs placed at the loaded end were carefully located on a portion of the steel rod between the wall and the rigid clamp and hinge in order to avoid interference from the test apparatus on the measurements.

\subsection{Test procedure}

The first monotonic test was carried out on specimen WT.40.I.1C under displacement control at a displacement rate of $5 \mu \mathrm{m} / \mathrm{s}$, with the purpose of capturing the post-peak behavior and preventing disruptive failures. The second monotonic test (WT.40.I.2C) doubled the displacement rate to $10 \mu \mathrm{m} / \mathrm{s}$, knowing that the later cyclic tests had to be performed at higher velocities. The stopping criteria adopted for the monotonic test were a $50 \%$ decrease in maximum load or the propagation of cracks beyond the expected area of damage. From these tests it was possible to define a cyclic procedure with at least two displacement amplitudes during the elastic phase and a minimum of three for softening phase. Amplitudes ranged from $2 \mathrm{~mm}$ to $18 \mathrm{~mm}$, with each one comprising two equal cycles and never unloading below $0.5 \mathrm{~mm}$. A maximum amplitude of $18 \mathrm{~mm}$ was established so that no damage could propagate to areas of surrounding tests. The range of velocities was between $10 \mu \mathrm{m} / \mathrm{s}$ to $40 \mu \mathrm{m} / \mathrm{s}$, respecting always a minimum of $120 \mathrm{~s}$ for duration of each loading or unloading branch. 


\section{MATERIAL CHARACTERIZATION}

The cement grout provided by $\mathrm{Cintec}^{\circledR}$ is part of their standard anchoring solution and presents $4.5 \mathrm{MPa}$ for tensile strength and 51.5 MPa for compressive strength, both at 28 days (values provided by $\mathrm{Cintec}^{\circledR}$ ). The steel ties of the anchoring system were made of stainless steel AISI 304 class 70, in order to keep them within the elastic range and prevent yielding.

Compression tests were carried out on masonry prisms, mortar cylinders and limestone cores. Diagonal compression tests were also performed on masonry wallets, in order to describe tensile and shear strengths. In order to achieve some of the mechanical properties of the historical masonry, a brief study on the mortar ratio was conducted, prior to construction of the specimens and considering the materials available for construction. As result, the mortar proportion of 1:3:10:6 (cement: hydraulic lime: river sand: clay-rich sand) was chosen. Slightly higher values of compressive strength than the ones described in section 1 were obtained, so that different failure modes could develop and not only masonry breakout. During construction of the pullout specimens, cylindrical mortar samples of $\phi 75 \times 150 \mathrm{~mm}^{3}$ were randomly collected and tested at the ages of 28 days and time of testing, 400 days. At both ages the average value of three specimens per age was 1.3 MPa (see Table 1), which suggested that after 28 days masonry specimens could be tested at any age without severe changes on the mortar mechanical properties.

The limestone came from Monsanto, an area outside Lisbon that historically supplied stone for construction of historical buildings. Five cylindrical cores were prepared and tested according to the ASTM D7012-10 [25] and Oliveira [26]. The specimens displayed an average diameter of $55 \mathrm{~mm}$ and an average length of $110 \mathrm{~mm}$ (length to diameter ratio of 2). The specimens' ends were machined flat. Until the time of testing, the specimens were kept under the same moisture conditions as the masonry walls, since it can have a significant effect upon the deformation of the rock. Compressive strength and elastic modulus are displayed in Table $\mathbf{1 .}$

The masonry specimens for the compression and diagonal compression tests were hand built, without the use of any formwork, the stones being distributed as random as possible. The specimens contained some imperfections like leaning, vertical joints continuous throughout the height of the prism, or thin horizontal joints allowing contact between stone units. Although accidental, these imperfections represent common aspects found in real masonry walls. 
Compression tests were carried out on two specimens, MP1 and MP2, at 90 days (one monotonic test and one cyclic test), while other three were tested at 400 days (around 13 months). The five masonry prisms have the dimensions $0.40 \times 0.50 \times 0.80 \mathrm{~m}^{3}$, following the recommendations of EN 1052-01:1999 [27]. Initially, the monotonic test enabled the determination of the value of the maximum compressive strength, which was then used to define the procedure for the cyclic tests. For the determination of the modulus of elasticity, the vertical displacement of the specimen was stabilized during the pre-peak phase by the means of steps with constant load or loading-unloading cycles. The cyclic procedure included two loading-unloading cycles at $25 \%$ and $50 \%$ of the maximum compressive strength (obtained from the monotonic test) carried out under force control (see Fig. 9a). After their completion a constant displacement rate was applied, ranging from $5 \mu \mathrm{m} / \mathrm{s}$ to $10 \mu \mathrm{m} / \mathrm{s}$. The low value adopted for the loading rate prevented abrupt failures and allowed stable failure processes capable of capturing the softening behavior of masonry [28]. Crack patterns formed initially in the central part of the specimen and then spread throughout, confirming a correct application of the load (see Fig. 9b). The average $f_{\mathrm{m}}$ of the first two specimens was 1.7 MPa, while for the remaining was $1.8 \mathrm{MPa}$. This slight variation was consistent with what was observed for the mortar, giving more freedom in terms of time to test. As previously discussed, values found in literature range between 0.50 and $1.50 \mathrm{MPa}$, thus placing the tested specimens slightly above the interval and directly correlating to the higher compressive strength chosen for the mortar. Specimen MP2 is not represented in Fig. 9a, and did not contribute to determine the elastic modulus, due to a malfunction of the LVDTs' acquisition system.

The diagonal compression tests were carried out in three masonry wallets, at the age of 124 days. The specimens were constructed as previously described, being later rotated of 45․ Although ASTM E 519-10 [29] suggests 1.2 m square specimens with the thickness that best describes the masonry under study, this study opted instead by a $0.8 \mathrm{~m}$ square wallet with $0.3 \mathrm{~m}$ thickness. This decision took into consideration the heavy weight of the final assemblage with relation to the low strength mortar and the need to transport and rotate the specimens to their final position. It is also noted that RILEM TC-76 LUM [30] does not specify dimensions of the specimens as long as they are representative of the finished masonry. The horizontal and vertical shear strains were determined and plotted versus the principal stresses (see Fig. 10a), which were calculated according to Frocht [31] theoretical approach. The typical crack pattern consisted of cracks along the vertical diagonal, opening at first in the center of the specimen and propagating to the extremities. The cracks occurred in the mortar and especially at the interface mortar-stone, due to the high difference in capacity of the two materials (see Fig. 10b). The average values 
obtained for the tensile and shear strengths were $0.14 \mathrm{MPa}$ and $0.29 \mathrm{MPa}$, respectively. From diagonal compression tests of masonry wallets with similar arrangement and materials, Milosevic et al. [32] obtained experimentally values of $0.22 \mathrm{MPa}$ and $0.18 \mathrm{MPa}$ for the tensile strength. Other authors that estimated the tensile strength from diagonal compression tests on random rubble stone masonry with air lime mortar reported the following ranges of values: 0.06-0.16 MPa [33] and 0.02-0.04 MPa [34].

In all tests, displacements were measured by LVDTs placed on the specimens. The elastic modulus was determined for the stone and masonry by performing a linear least squares fit to the straight-line portion of the stress-strain curves. Compressive, tensile and shear strengths, and elastic modulus with respective coefficients of variation $(\mathrm{CoV}$ in $\%)$ of the materials characterized experimentally are presented in Table 1.

\section{RESULTS}

\subsection{Hysteretic curves}

Of the 8 tests prepared initially in the two walls, only 7 were carried out successfully due to an equipment malfunction. A total of 2 monotonic and 5 quasi-static cyclic pullout tests were performed. An immediate observation of the resistance pointed out the difference between tests conducted at top and bottom of the wall (see

Table 2), with a difference of approximately $30 \%$ in ultimate load, which is discussed in section 5 . At the base of the wall the average maximum pullout force was $107.9 \mathrm{kN}$, while at the top the same parameter reached $76.8 \mathrm{kN}$, both with a $\mathrm{CoV}$ below $5 \%$. These values correspond to the load required to pullout the pair of anchors, simultaneously. Displacements and other parameters presented in Table 2, also account for the combined behavior of both anchors. The initial stiffness $\left(k_{0}\right)$, the yield displacement $\left(d_{\mathrm{y}}\right)$, and the ultimate displacement $\left(d_{\mathrm{u}}\right)$, referring to the pair of injection anchors, were estimated based on the total slip $\left(s_{\mathrm{T}}\right)$ (see Fig. 7a), which accounted for the contributions of all possible failure modes. The calculation of $k_{0}$ was done with a linear least squares fit on the linear portion of the ascending branch of the first cycle of the $2 \mathrm{~mm}$ step. The yield displacement was taken as the displacement when first yielding occurs and the ultimate displacement corresponded to the post-peak displacement when a loss of $20 \%$ load carrying capacity happened [35]. The ratio between $d_{\mathrm{u}}$ and $d_{\mathrm{y}}$ is the displacement ductility factor, $\mu$, which expresses the energy dissipation capacity of the strengthening. The initial stiffness and displacements display great variability, with $\mathrm{CoV}$ ranging from $5 \%$ to $75 \%$. Still, specimens at the bottom of the wall have in average a smaller ductility factor than the ones at the top. Specimen WT.40.I.1C presents a completely 
different force-displacement curve compared to others (see Fig. 11a) with much lower stiffness (17 kN/mm) and a slower decrease in load immediately after the peak followed by an abrupt drop of load (35\%) at approximately $13.5 \mathrm{~mm}$. This drop corresponded to a clear detachment of a small portion of the front face of the wall around the anchor that was further from the lateral edge of the wall, which was not consistent with the behavior observed for the remaining tests. Also, the stiffness and ductility factor determined for specimen WT.40.I.1D are very high compared to the other specimens. The difference on the observed behaviors lies on the masonry and on the interface grout/masonry, which will be discussed in section 5 .

Fig. 11 shows the envelope curves of the tests performed on both walls, except the one of WT.40.I.2A due to problems with the instrumentation. Force-displacement curves display a long linear branch until $50 \%$ to $85 \%$ of the peak load, with the higher percentages belonging to the tests performed on Wall 1 . The softening branch in all tests tended to an ultimate load interval between $35 \mathrm{kN}$ to $45 \mathrm{kN}$, even for specimens WT.40.I.1C and WT.40.I.1D. This is most likely related with friction of the interface grout/masonry and the compression state of the walls.

Force-displacement hysteresis loops of specimens WT40.I.2C and WT.40.I.1A represent the typical curves of tests performed at the top (see Fig. 12a) and bottom (see Fig. 12b) of the wall, respectively. As can be observed, the pinched hysteresis loops show great similarity and are controlled by bond slip phenomena at the grout/masonry interface. The cyclic behavior shows a degradation of force and stiffness with the increasing steps and an accumulation of residual displacements. The descending branches of the cycles pushed the specimen as much as $0.5 \mathrm{~mm}$, which caused the development of compressive forces. The values of this force obtained for top and bottom of the walls were very close $(21.0 \mathrm{kN}$ and $23.9 \mathrm{kN})$, not portraying the clear distinction noticed for tension. Residual displacements and compression forces depend greatly on the composition of the interface grout/masonry and surrounding masonry.

Fig. 13a presents the force-displacement curves for the front of the wall, considering the average of the displacements from positions 2 to 12 (see Fig. 7b), except numbers 6 and 8, which correspond to the anchors. All tests presented considerable accumulation of residual displacements after the peak load due to the appearance of cracks, which continued to open as the test progressed. At the back of the wall a snap-back effect on the curve was clear, after the peak, meaning that the back face of the wall was no longer being engaged in the full response and the masonry cone breakout occurred (see Fig. 13b). At both front and back faces of the wall, tests performed at the bottom of the wall engaged the wall less than the ones at the top, with much smaller displacements. 


\subsection{Energy dissipation}

From the force-displacement curves based on $s_{\mathrm{T}}$ (see Fig. 12), it was possible to analyze total energy, energy dissipation, and force degradation over the 8 steps of the cyclic procedure. The total energy accounts for the elastic energy and the dissipated energy, and is determined by taking the integral of the force-displacement curve. In this particular case, it is of great interest to study the energy released in total by the grout/masonry interface and by the masonry cone. Since $s_{\mathrm{T}}$ accounts for both the grout/masonry interface $\left(s_{\mathrm{L}}\right)$ and masonry cone displacements, the difference between $s_{T}$ and $s_{L}$ gives an estimation of the contribution of the masonry cone alone.

The tests performed at the bottom of the wall (WT.40.I.1A and WT.40.I.2B) resulted in energy curves that have a good agreement among them (see Fig. 14). The curves for the tests performed at the top of the wall (WT.40.I.1D and WT.40.I.2C) show very different ranges of total energy as well as cumulative displacement. The differences between WT.40.I.1D and WT.40.I.2C can be explained mainly by large displacements in the pair of anchors in WT.40.I.1D, rather than a large increase in force (in this case only 8\%). The specimens WT.40.I.1A and WT.40.I.1D presented total energy curves very similar for $s_{\mathrm{T}}$ and $s_{\mathrm{L}}$. As it can be observed in Fig. 14a, the concavity of the curves has a tendency to weaken with the progression of the test due to the high residual displacements verified at the cracked face of the wall.

The dissipated energy per step and cycle, shown in Fig. 15, gives better insight of the response through the development of the failure mode. Tests WT.40.I.1A and WT.40.I.2B (bottom of the wall) had peaks at $8 \mathrm{~mm}$ and $12 \mathrm{~mm}$ steps for the $1^{\text {st }}$ cycle, respectively. This release of energy occurred during the step after the peak load was reached: $6 \mathrm{~mm}$ and $10 \mathrm{~mm}$ steps, respectively. Tests WT.40.I.1D and WT.40.I.2C presented smoother curves, always with a tendency to increase, as shown in Fig. 15a. On the other hand, cycle repetition does not have such distinct peaks and less energy is dissipated (see Fig. 15b).

The dissipated energy per displacement contributions (grout/masonry interface and cone) calculated for each test shows that the tests performed at the bottom of the wall have a higher contribution from the interfaces than the ones performed at the top. Tests WT.40.I.1A and WT.40.I.2B showed little contribution from the masonry cone, with values ranging from 5\% to $12 \%$. On the other hand, WT.40.I.1D and WT.40.I.2C relied more on masonry cone failure, but with less extreme contributions of the interface: $38 \%$ and 22\% (see Fig. 16a). 
Strength degradation between cycles was also determined for each step of the cyclic procedure (see Fig. 16b) and there is a great deal of variability between tests. Again, tests WT.40.I.1A and WT.40.I.2B showed higher strength loss in the steps after the peak load was reached. This explains why the peaks are barely noticeable on the dissipated energy of the $2^{\text {nd }}$ cycle (see Fig. 15b). For the tests at the top of the wall (WT.40.I.1D and WT.40.I.2C) higher values of strength degradation were observed for the next 2 to 3 steps after the peak load. At the $18 \mathrm{~mm}$ step (last step), each test had the following strength reduction: WT.40.I.2B - 51\%, WT.40.I.1A - 62\%, WT.40.I.2C - 30\%, and WT.40.I.1D - 58\%.

\subsection{Post-test inspection}

After performing the tests, specimens were demolished and carefully surveyed in order to look for physical evidence of the failure modes and other aspects that could influence the output. A clear masonry cone failure was observed on tests performed on the top of the wall, as shown in Fig. 17a (arrows indicate the direction of the pullout force). These tests evidenced a failure cone angle between $45^{\circ}$ and $50^{\circ}$ (see Fig. 17a), which confirmed the initial assumption and results from the energy dissipation analysis. This survey showed an overlap between failure cones, which is a direct result of the proximity between injection anchors. Also, it can be observed that the formation of the cone did not initiate at the free end of the anchor, as shown in Fig. 17b. Due to the big difference in resistance between mortar and stone, cracks propagated through mortar-especially through mortar/stone interface.

For tests performed on the bottom wall, little evidence of a fully formed masonry cone failure was found. Fig. 18a shows the combined result of sliding between the interface grout/masonry and detachment of masonry. This was observed for all tests. The grout plug of the anchors had transversal and longitudinal cracking - a phenomenon also observed by Gigla [15] — and in some cases a cone-shaped segment of the mortar plug detached from the free end of the anchor (see Fig. 18b).

All injection anchors were measured after testing and the interfaces grout/masonry were studied. As shown in Fig. $\mathbf{1 8 b}$, it was possible to observe that anchor's diameter varied with the type of surface existing in the hole and that the sock expanded more when in contact with mortar. While diameter of the borehole was $\phi 50 \mathrm{~mm}$, the anchor diameters ranged from $49.9 \mathrm{~mm}$ to $63.6 \mathrm{~mm}$, with an average of $56 \mathrm{~mm}$. The largest anchor diameters were in fact over $10 \mathrm{~mm}$ greater than core size. 


\section{DISCUSSION OF RESULTS}

The location of the anchors on the wall was specifically chosen so that the masonry cone failure could fully develop. This was done by keeping the distance to all edges greater than the embedment length. A compromise had to be made when idealizing the test apparatus - the steel supports overlapped $7 \%$ of the projected area of the masonry cone. Therefore, there can be a small confinement resultant from this overlap.

The monotonic test, WT.40.I.1C, presented a different force-displacement curve compared to other tests (see Fig. 11), with lower stiffness and a rough softening branch that could have been related to a different arrangement of the masonry wall or the grout/masonry interface.

All tests showed combined cone-bond failure with sliding at the interface grout/masonry and masonry breakout. Energy dissipation quantification (see Fig. 16a) confirmed what was observed during visual inspection: tests at the top showed a higher influence of the masonry cone while tests at the bottom showed bond failure at the interface grout/masonry as the major contributor for failure. The different behavior in failure is apparently linked to the high discrepancy in tensile capacity between top and bottom anchors.

Tests were carried out from bottom to top, but when large differences in force were observed it was decided to perform test WT.40.I.1C (top anchors) before others. Regardless, the same difference in load was observed. A possible interference between tests sequence was thus discarded as an explanation for the difference in behavior. The source of this $30 \%$ difference in load may lie in the different boundary conditions of the wall. The bottom of the wall was supporting directly on the lower concrete slab, while the top of the wall had the steel profiles and the hydraulic cylinders between it and the upper reaction slab. Especially the hydraulic cylinders, constituted much slender elements than the rest, leading to rotation of the upper part. Evidence of this phenomenon, was the continuous need for adjustment of the pressure necessary to keep the compressive state of the wall constant. The pressure slightly increased while pulling and decreased while pushing. Also, tests carried out close to the base of the wall consistently showed smaller displacements, as presented in Fig. 13. Therefore, it is likely that the test set up created a fixed support at the bottom and a pinned support at the top of the wall. This can explain the different behaviors of the tests in different locations, including the predominance of the failure modes. Further studies of anchors with different boundary conditions are required to answer the distinct behavior observed, but the lower values obtained in the tests can be adopted on the safe side.

Since boundary conditions were the main factor affecting the results, it is difficult to derive any influence of the diameter of the steel rods. The existence of a washer at the free end of the anchors prevented, as expected, 
occurrence of sliding at the interface steel rod/grout. Also, the high grade of steel class excluded yielding of the rod and kept it within the elastic range. Both factors tend to assure that the diameter of the rod had a small influence on the results.

The envelop force-displacement curves (see Fig. 11), especially of the tests performed at the bottom, towards the end of the softening branch tend to a force interval between $35 \mathrm{kN}$ to $45 \mathrm{kN}$, which is an effect of friction at the interface grout/masonry or in the cone region due to the presence of vertical load on the wall. When drilling the holes for installation, installing the injection anchors, and carrying out the test, the walls were always under a compressive state. Therefore, sliding at the interface has the contribution of cohesion (right after the peak) and internal friction, which is the tangent of the friction angle multiplied by the normal stress (tendency for a horizontal plateau). A similar effect can occur at the cone due to crack dilatancy and wall confinement.

In spite of the variability obtained for the ductility factor, one must point out that the strengthened connections presented ductility factors above 2 , which is favorable for seismic performance. It means that the connection has the ability to undergo considerable amount of deformation in the plastic range with a reduction in strength up to $20 \%$. The average ductility of the tests at the bottom of the wall (equal to 3.1) is lower than the one determined for the top (equal to 6.3), if the specimen WT.40.I.1D is excluded. Once again, putting on evidence the different behavior observed.

While test performed on the bottom of the wall present good agreement in terms of total and dissipated energy, tests at the top show different behaviors. In both cases, energy dissipation between $1^{\text {st }}$ and $2^{\text {nd }}$ cycles is smaller because of the sliding occurring on the grout/masonry interface before the anchor regains strength.

\section{CONCLUSIONS}

The tests were successfully executed, since many of the initial considerations were confirmed, but also new questions were raised. This research adds critical experimental information about the behavior of parallel injection anchors for wall-to-timber elements connections or similar applications in stone rubble masonry.

Boundary conditions seem to have provided a distinct behavior between anchors at the top and bottom of the wall in terms of force-displacement curve, maximum pullout force, and failure mode type (bond and/or cone failure). Higher values of maximum pullout force were determined for tests performed at the base of the wall, with an average value of $107.9 \mathrm{kN}$. Tests at the top showed a $30 \%$ decrease in that value, reaching $76.8 \mathrm{kN}$. All tests 
showed combined cone-bond failure, with higher contribution of the bond slip in the tests performed at the bottom and higher participation in failure of the cone breakout in tests performed at the top.

The compressive stress of the wall influenced the behavior of the injection anchors, which was especially noted with the contribution of internal friction in the softening branch of the curve.

Further work on pullout tests of single injection anchors is recommended, in order to study the influence of boundary conditions and distance between anchors. Since this research studied the anchoring system to the wall, the injection anchors, and disregarded the contribution of the timber elements, future developments should also focus on studying the behavior of the complete assembly.

\section{ACKNOWLEDGEMENTS}

This work was partially funded by project FP7-ENV-2009-1-244123-NIKER of the $7^{\text {th }}$ Framework Program of the European Commission, which is gratefully acknowledged. Authors would like to thank the technical staff of the Structures Lab. of University of Minho for the assistance provided preparing and carrying out the tests and also, Monumenta, Ltd. for the construction of the masonry walls and $\mathrm{Cintec}^{\circledR}$ for the installation of the injection anchors. 


\section{REFERENCES}

[1] Ramos LF, Lourenço PB. Modeling and vulnerability of historical city centers in seismic areas: a case study in Lisbon. Eng Struct. 2004;26(9):1295-310.

[2] Yi T, Moon FL, Leon RT, Kahn LF. Lateral Load Tests on a Two-Story Unreinforced Masonry Building. J Struct Eng. 2006;132(5):643-52.

[3] Parisi MA, Piazza M. Seismic behavior and retrofitting of joints in traditional timber roof structures. Soil Dyn Earthq Eng. 2002;22(9-12):1183-91.

[4] Lin TJ, LaFave JM. Experimental structural behavior of wall-diaphragm connections for older masonry buildings. Constr Build Mater. 2012;26:180-9.

[5] Bento R, Lopes M, Cardoso R. Seismic evaluation of old masonry buildings. Part II: Analysis of strengthening solutions for a case study. Eng Struct. 2005;27:2014-23.

[6] Senaldi I, Magenes G, Ingram JM. The seismic performance of unreinforced stone masonry building during the 2010-2011 Canterbury earthquake sequence. Proceedings of the 15th World Conference on Earthquake Engineering. Lisbon, Portugal; 2012.

[7] Mascarenhas J. Construction Systems - V, The "Pombalino" Buildings of downtown Lisbon (in Portuguese). 2nd ed. Lisboa: Livros Horizonte; 2004.

[8] Pinho F. Walls of Old Buildings in Portugal (in Portuguese). 1st ed. Lisboa: LNEC; 2008.

[9] Appleton J. Rehabilitation of "Gaioleiro" Buildings (in Portugusese) 1st ed. Amadora: Edições Orion; 2005.

[10] Silva VCE, Soares I. Seismic Vulnerability of Lisbon's “Gaioleiro" buildings and possible measures to reduce it (in Portuguese). 3o Encontro sobre Sismologia e Engenharia Sísmica. Lisbon, Portugal; 1997.

[11] Cardoso R. Seismic Vulnerability of old masonry structures - Aplication to a "Pombalino" building (in Portuguese). UTL/IST; 2003.

[12] Silva VCE. Structural Rehabilitation of Old Buildings (in Portuguese). Lisboa: Argumentum; 2007.

[13] Mendes N, Lourenço PB. Seismic Assessment of Masonry “Gaioleiro” Buildings in Lisbon, Portugal. J Earthq Eng. 2009;14:80-101.

[14] Tomaževič M. Earthquake-resistant design of masonry buildings, Innovation in Structures and Construction, Vol. 1. London: Elnashai AS \& Dowling PJ, Imperial College Press; 1999. 
[15] Gigla B. Bond strength of injection anchors as supplementary reinforcement inside historic masonry. Proceedings of the 13th International Brick and Block Masonry Conference. Amsterdam; 2004. p. 11928.

[16] Comité Euro-International du Béton (CEB). Fastenings to Concrete and Masonry Structures. State-ofthe-art report. London: Thomas Telford; 1994.

[17] Cook RA, Burtz JL, Ansley MH. Design Guidelines and Specifications for Engineered Grouts. Gainsville, Florida; 2003.

[18] Zamora NA, Cook RA, Konz RC, Consolazio GR. Behavior and Design of Single, Headed and Unheaded, Grouted Anchors under Tensile Load. ACI Struct J [Internet]. 2003 [cited 2014 Apr 5];100(2):222-30. Available from: http://www.concrete.org/Publications/ACIMaterialsJournal/ACIJournalSearch.aspx?m=details\&ID=124 $\underline{86}$

[19] Eligehausen R, Cook RA, Appl J. Behavior and Design of Adhesive Bonded Anchors. ACI Struct J [Internet]. 2006;103:822-31. Available from: http://www.refdoc.fr/Detailnotice?idarticle=6323318

[20] Cook RA, Kunz J, Fuchs W, Konz RC. Behavior and design of single adhesive anchors under tensile load in uncracked concrete. Aci Struct J. 1998;95:9-26.

[21] Algeri C, Poverello E, Plizzari G, Giuriani E. Experimental Study on the Injected Anchors Behaviour on Historical Masonry. Adv Mater Res. 2010;133-134:423-8.

[22] Arifovic F, Nielsen MP. Strength of anchors in masonry. 2004.

[23] CEN/TC 250/SC5. EN 1995-1-1:2004. Eurocode 5 - Design of timber structures - Part 1-1: General Common rules and rules for buildings. Brussels, Belgium; 2004.

[24] CEN/TC 250/SC1. EN 1991-1-1: 2002. Eurocode 1: Actions on structures - Part 1-1: general actions Densities, self-weight, imposed loads for buildings. Brussels, Belgium; 2002.

[25] ASTM D7012-10. Standard Test Method for Compressive Strength and Elastic Moduli of Intact Rock Core Specimens under Varying States of Stress and Temperatures. West Conshohocken, PA: ASTM International; 2010.

[26] Oliveira D V. Experimental and numerical analysis of blocky masonry structures under cyclic loading. University of Minho; 2003. 
[27] CEN. EN 1052-1:1999 - Methods of test for masonry. Determination of compressive strength. Brussels, Belgium; 1999.

[28] Vasconcelos GFM. Experimental investigations on the mechanics of stone masonry: Characterization of granites and behavior of ancient masonry shear walls. University of Minho; 2005. p. 266.

[29] ASTM International. ASTM E519 / E519M - 10. Standard Test Method for Diagonal Tension (Shear) in Masonry Assemblages. West Conshohocken, PA; 2010.

[30] Committee RT. RILEM TC 76-LUM. Diagonal tensile strength of small walls specimens. 1994.

[31] Frocht M. Recent advances in photoelasticity. ASME Trans. 1931;55(September-December):135-53.

[32] Milosevic J, Gago AS, Lopes M, Bento R. Experimental assessment of shear strength parameters on rubble stone masonry specimens. Constr Build Mater [Internet]. Elsevier Ltd; 2013 Oct [cited 2014 Mar 21];47:1372-80. Available from: http://linkinghub.elsevier.com/retrieve/pii/S0950061813005540

[33] Chiostrini S, Galano L, Vignoli A. On the Determination of Strength of Ancient Masonry Walls via Experimental Tests. 12th World Conference on Earthquake Engineering [Internet]. 2000. p. 1-8. Available from: http://www.iitk.ac.in/nicee/wcee/article/2564.pdf

[34] Brignola A, Frumento S, Lagomarsino S, Podestà S. Identification of Shear Parameters of Masonry Panels Through the In-Situ Diagonal Compression Test. Int J Archit Herit [Internet]. 2008 Dec 2 [cited 2014 Mar 21];3(1):52-73. Available from: http://www.tandfonline.com/doi/abs/10.1080/15583050802138634

[35] Park R. Evaluation of ductility of structures and structural assemblages from laboratory testing. Bull New Zeal Soc Earthq Eng. 1989;22(2):155-66. 


\section{List of Tables}

Table 1 Mechanical properties of tested materials ( $\mathrm{CoV}$ is given in parentheses, in \%)

Table 2 Performance parameters of the pullout tests

\section{List of Figures}

Fig. 1 Different type of wall-to-half-timbered wall connections (adapted from Cardoso [11]).

Fig. 2 Strengthening solutions: (a) anchoring floor joists to masonry walls with steel ties with anchor plates (adapted from [14]); (b) anchoring half-timbered walls to masonry walls through injection anchors [12].

Fig. 3 Failure modes: (a) bond failure at grout/masonry interface; (b) combined cone-bond failure.

Fig. 4 Masonry typology: (a) surrounding the anchors; (b) during construction.

Fig. 5 Scheme adopted for the specimens of the pullout test (dimensions in $\mathrm{mm}$ ).

Fig. 6 Apparatus for monotonic and cyclic pullout tests (dimensions in mm): (a) perspective; (b) elevation view.

Fig. 7 Instrumentation: (a) idealized model of the displacements to be measured; (b) sketch of the LVDTs positions.

Fig. 8 Instrumentation: (a) distribution on the front face of the wall; (b) distribution on the back face of the wall.

Fig. 9 Compression test of masonry prisms: (a) stress-strain curves; (b) typical crack pattern.

Fig. 10 Diagonal compression test of masonry wallets: (a) stress-strain curves; (b) typical crack pattern.

Fig. 11 Envelope curves based on $s_{T}$ : (a) Wall 1; (b) Wall 2.

Fig. 12 Typical force-displacement curves for cyclic tests, based on $s_{T}$ : (a) bottom of the wall; (b) top of the wall.

Fig. 13 Force-displacement curves of the wall: (a) front face of the wall; (b) back face of the wall.

Fig. 14 Total energy analysis (a) based on $s_{T}$; (b) based on $s_{\mathrm{L}}$.

Fig. 15 Dissipated energy analysis per cycle: (a) $1^{\text {st }}$ cycle; (b) $2^{\text {nd }}$ cycle.

Fig. 16 (a) Energy dissipation per displacement contributions (interface and cone); (b) Percentage of force degradation between cycles per step.

Fig. 17 Formation of the masonry cone: (a) top view of a fully formed cone; (b) cone intersecting the anchors

Fig. 18 Survey after testing: (a) sliding on the interface grout/masonry with detachment of a shallow masonry cone; (b) injection anchors after testing. 
Table 1 Mechanical properties of tested materials (CoV is given in parentheses, in \%)

\begin{tabular}{cccc} 
Properties & Mortar & Limestone & Masonry \\
\hline Compressive strength (MPa) & $1.3(16 \%)$ & $106.7(8 \%)$ & $1.7(10 \%)$ \\
Shear strength (MPa) & - & - & $0.29(15 \%)$ \\
Tensile strength (MPa) & - & - & $0.14(15 \%)$ \\
Elastic modulus (MPa) & - & $51500(17 \%)$ & $1015(14 \%)$
\end{tabular}


Table 2 Performance parameters of the pullout tests

\begin{tabular}{|c|c|c|c|c|c|c|}
\hline Specimen & $\begin{array}{l}\text { Type of } \\
\text { pullout }\end{array}$ & $\begin{array}{l}\text { Maximum } \\
\text { force }(k N)\end{array}$ & $\begin{array}{c}k_{0} \\
(k N / \mathbf{m m})\end{array}$ & $\Delta_{\mathrm{y}}(\mathbf{m m})$ & $\Delta_{\mathrm{u}}(\mathbf{m m})$ & $\mu$ \\
\hline WT.40.I.1A & Cyclic & 111.7 & 33.3 & 2.5 & 6.8 & 2.7 \\
\hline WT.40.I.2A & Cyclic & 107.2 & - & - & - & - \\
\hline WT.40.I.2B & Cyclic & 104.9 & 35.1 & 2.7 & 9.53 & 3.5 \\
\hline \multicolumn{2}{|c|}{ Bottom average } & 107.9 & 34.2 & 2.6 & 8.2 & 3.1 \\
\hline \multicolumn{2}{|r|}{$\operatorname{CoV}(\%)$} & 3.2 & 3.7 & 5.4 & 23.6 & 18.3 \\
\hline WT.40.I.1C & Monotonic & 76.8 & 18.2 & 3.1 & 16.8 & 5.4 \\
\hline WT.40.I.1D & Cyclic & 81.2 & 62.0 & 0.7 & 12.1 & 18.6 \\
\hline WT.40.I.2C & Cyclic & 75.0 & 40.9 & 0.9 & 6.7 & 7.4 \\
\hline \multirow{3}{*}{ WT.40.I.2D } & Monotonic & 74.3 & 40.2 & 1.3 & 7.7 & 5.9 \\
\hline & Top average & 76.8 & 40.3 & 1.5 & 10.8 & 9.4 \\
\hline & $\operatorname{CoV}(\%)$ & 4.0 & 44.4 & 74.5 & 42.7 & 66.7 \\
\hline
\end{tabular}




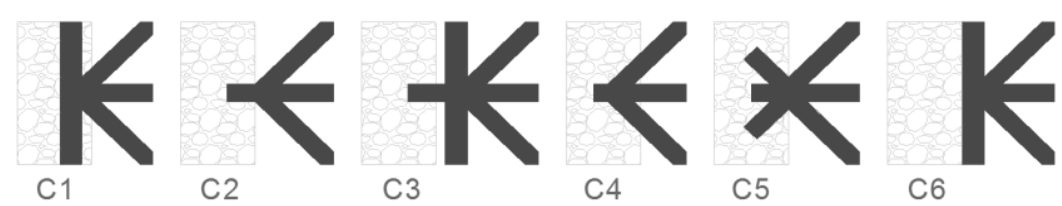

Fig. 1 Different type of wall-to-half-timbered wall connections (adapted from Cardoso [11]). 


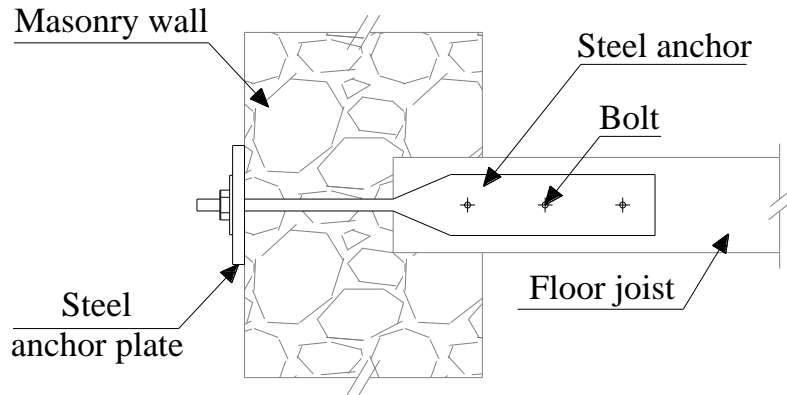

(a)

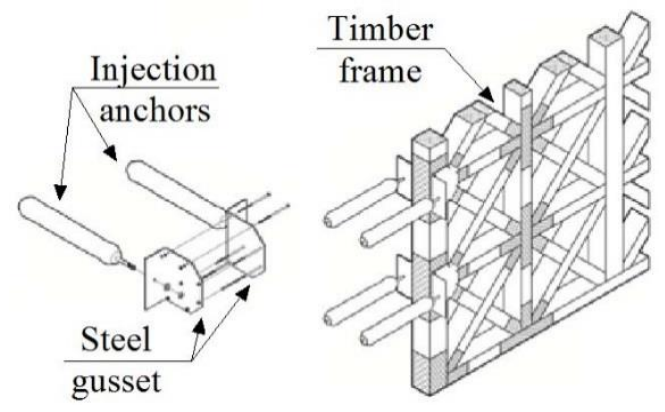

(b)

Fig. 2 Strengthening solutions: (a) anchoring floor joists to masonry walls with steel ties with anchor plates (adapted from [14]); (b) anchoring half-timbered walls to masonry walls through injection anchors [12]. 


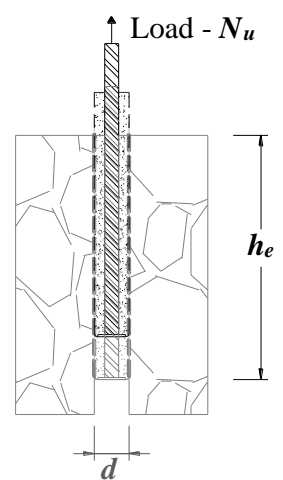

(a)

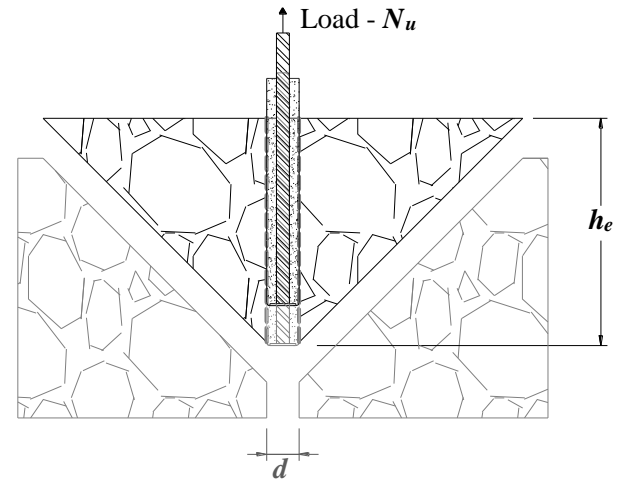

(b)

Fig. 3 Failure modes: (a) bond failure at grout/masonry interface; (b) combined cone-bond failure. 


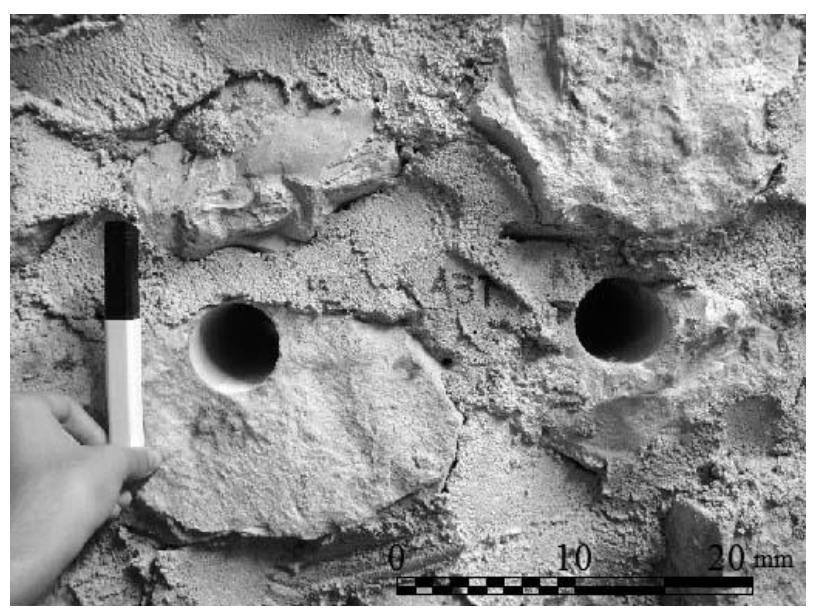

(a)

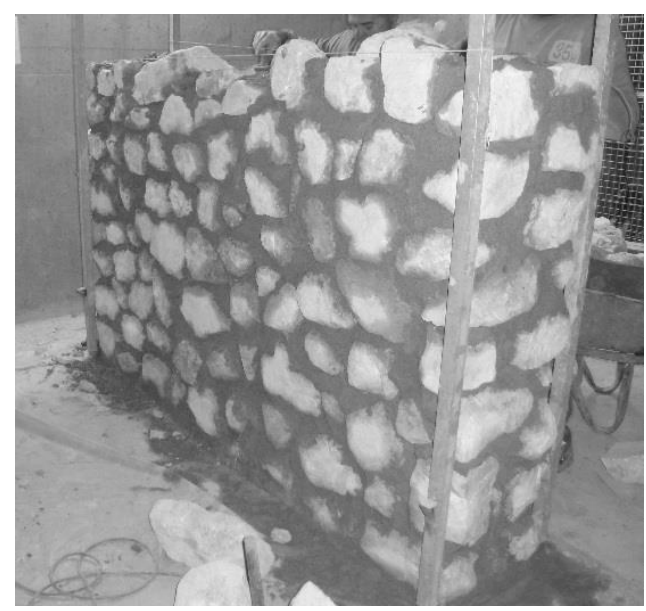

(b)

Fig. 4 Masonry typology: (a) surrounding the anchors; (b) during construction. 


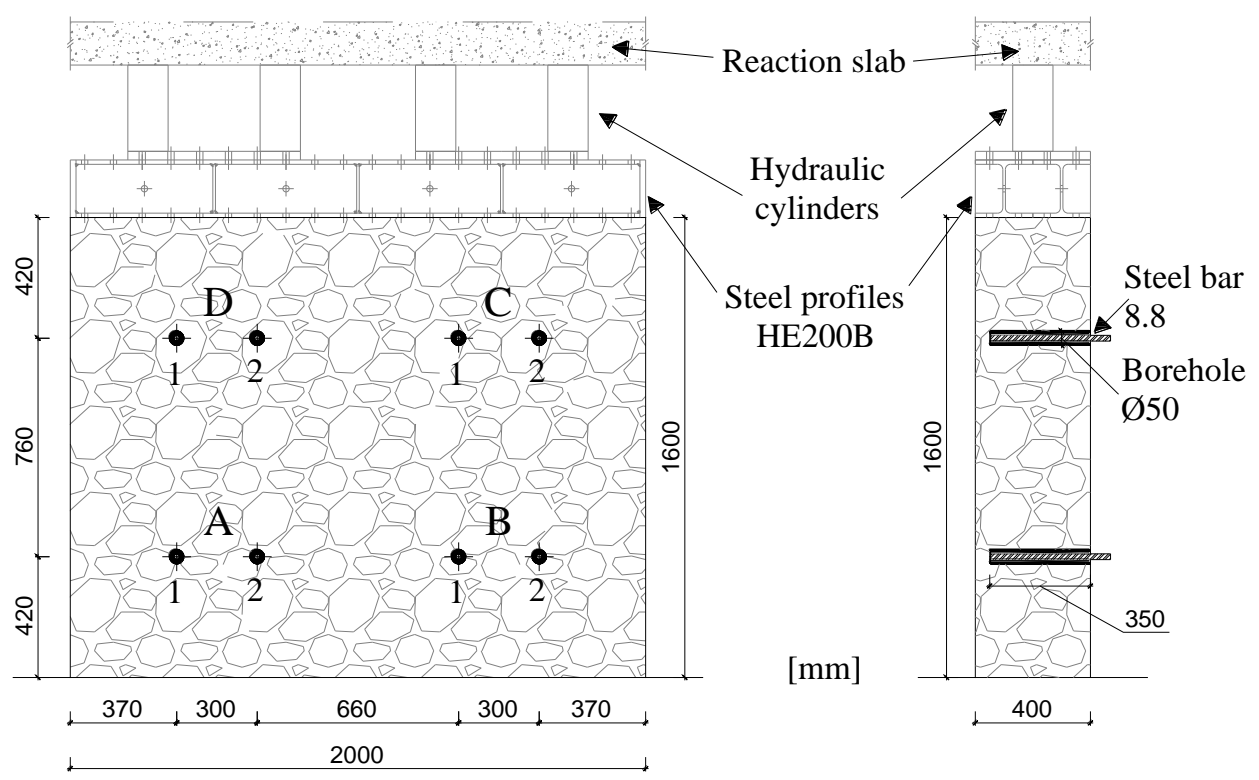

Fig. 5 Scheme adopted for the specimens of the pullout test (dimensions in $\mathrm{mm}$ ). 


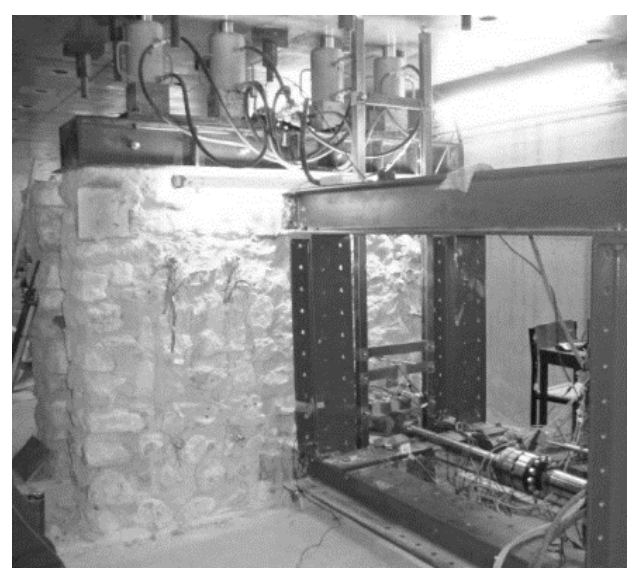

(a)

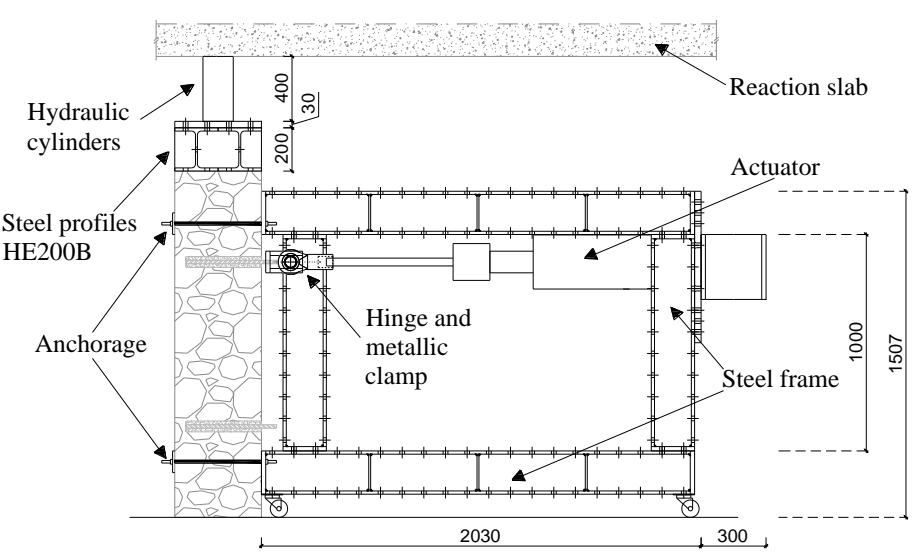

(b)

Fig. 6 Apparatus for monotonic and cyclic pullout tests (dimensions in mm): (a) perspective; (b) elevation view. 


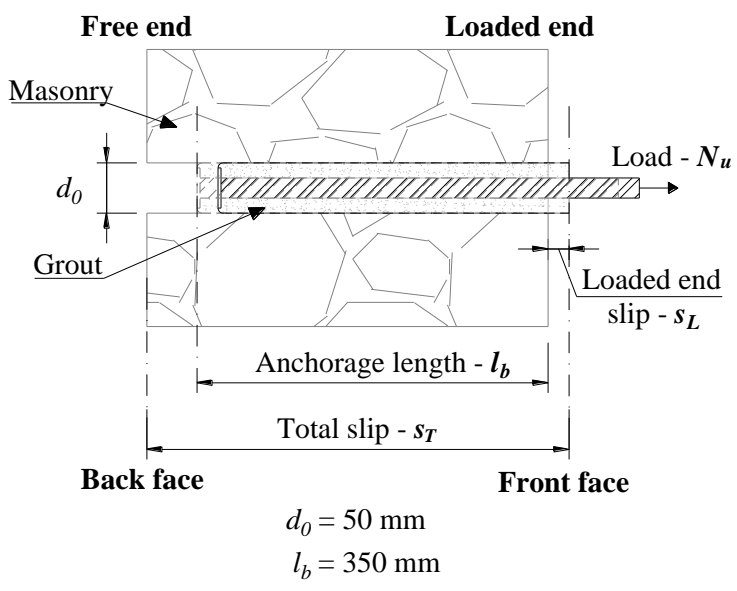

(a)

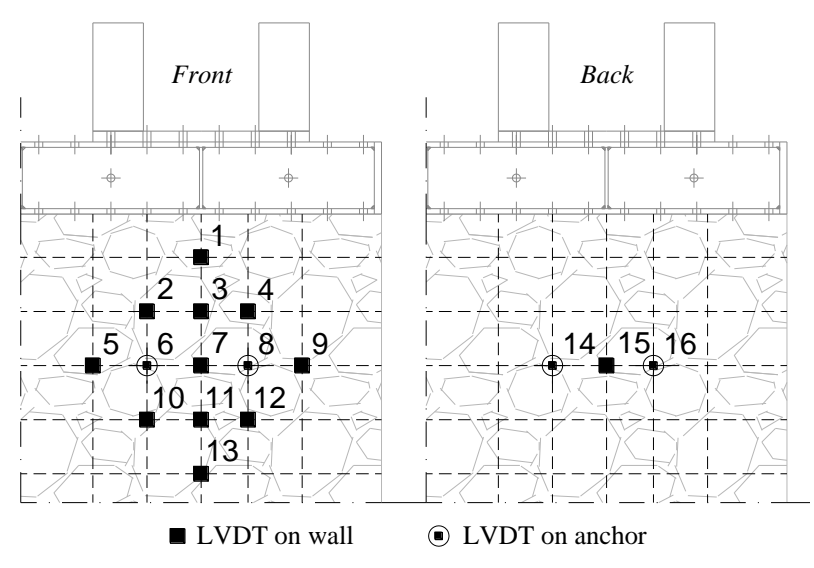

(b)

Fig. 7 Instrumentation: (a) idealized model of the displacements to be measured; (b) sketch of the LVDTs positions. 


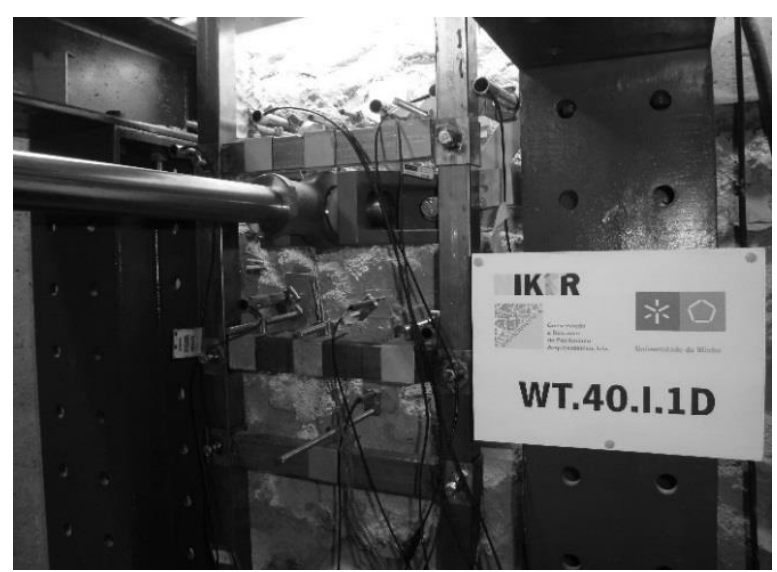

(a)

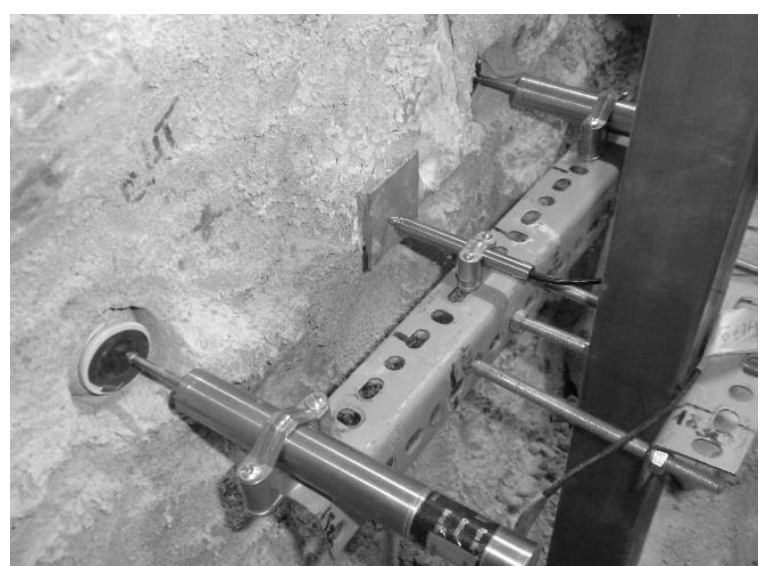

(b)

Fig. 8 Instrumentation: (a) distribution on the front face of the wall; (b) distribution on the back face of the wall. 


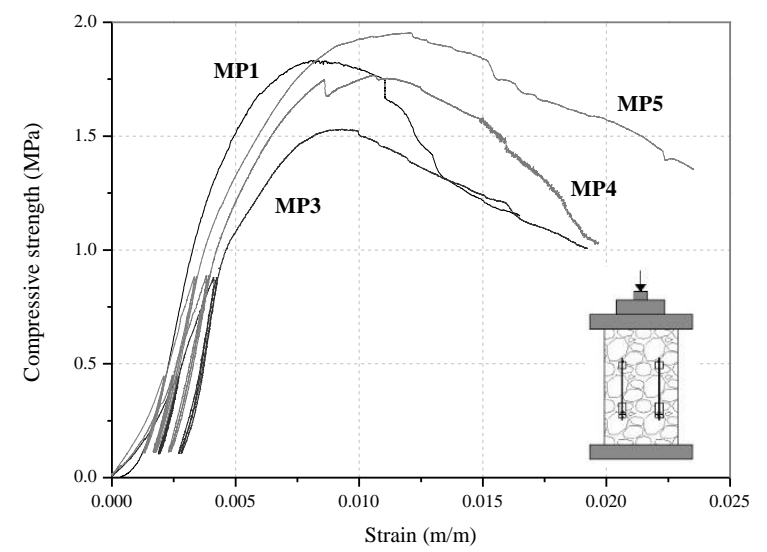

(a)

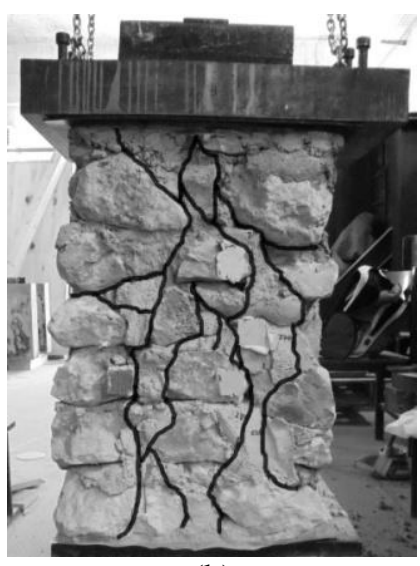

(b)

Fig. 9 Compression test of masonry prisms: (a) stress-strain curves; (b) typical crack pattern. 


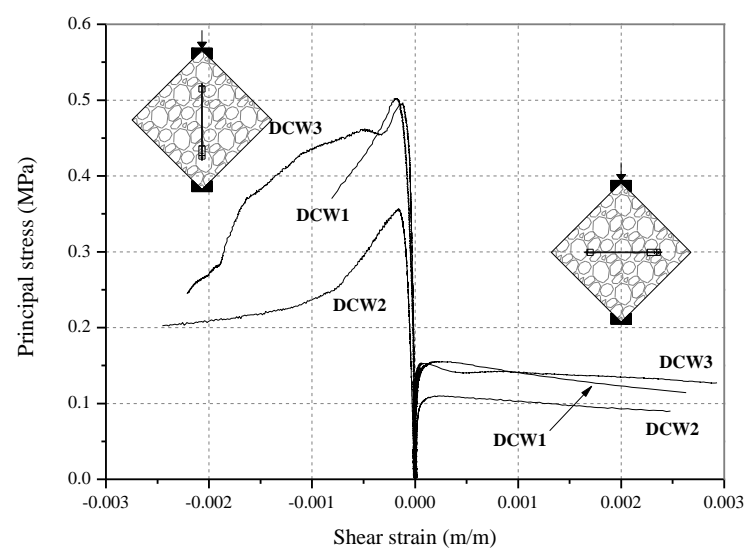

(a)

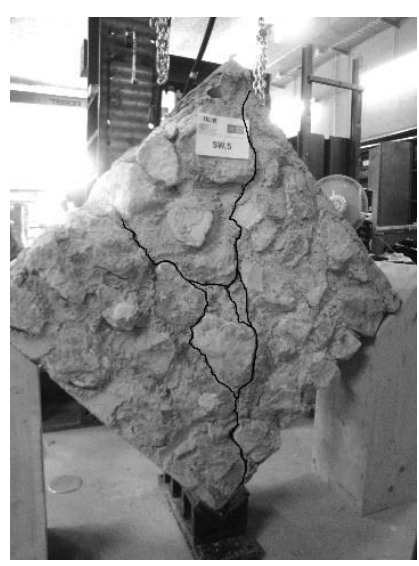

(b)

Fig. 10 Diagonal compression test of masonry wallets: (a) stress-strain curves; (b) typical crack pattern. 


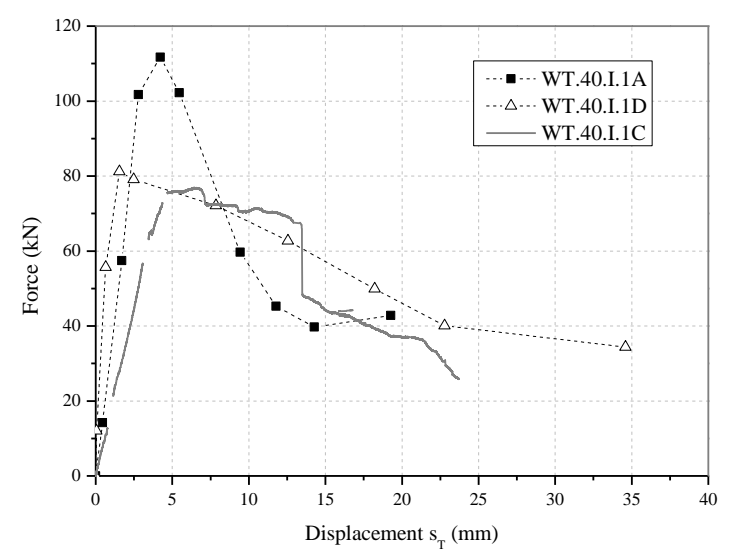

(a)

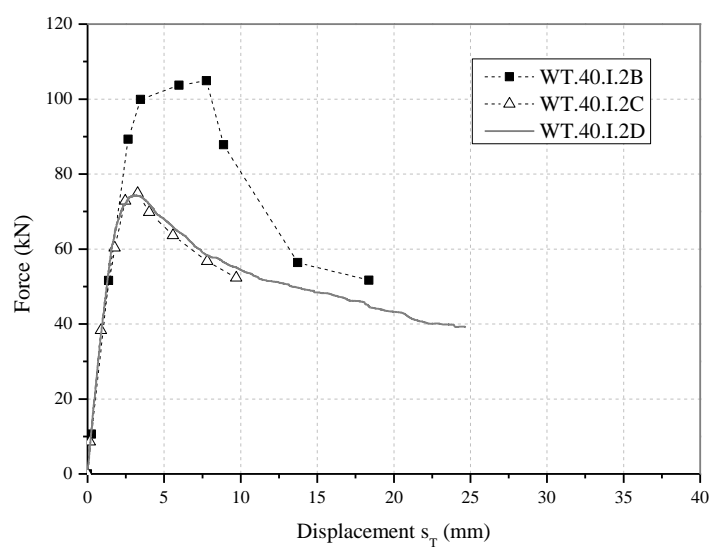

(b)

Fig. 11 Envelope curves based on $s_{T}$ : (a) Wall 1; (b) Wall 2. 


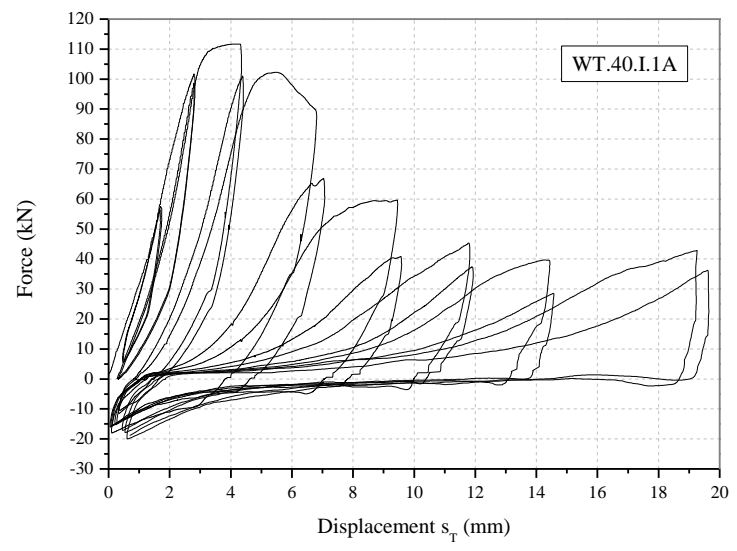

(a)

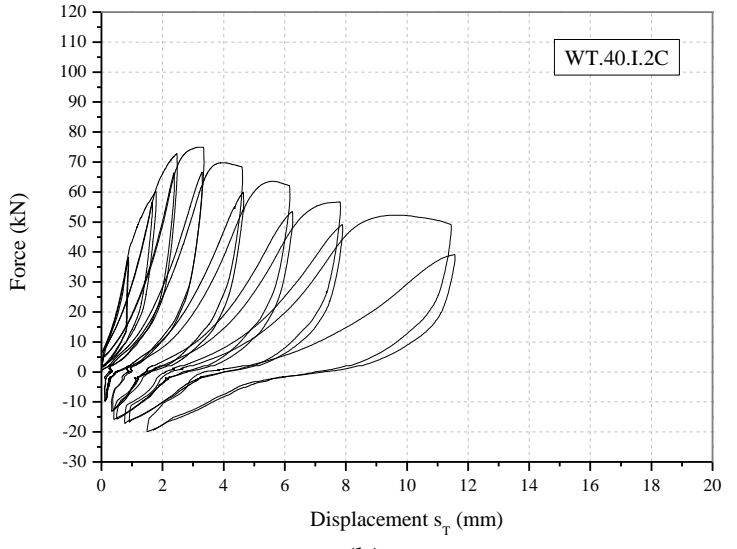

(b)

Fig. 12 Typical force-displacement curves for cyclic tests, based on $s_{T}$ : (a) bottom of the wall; (b) top of the wall. 


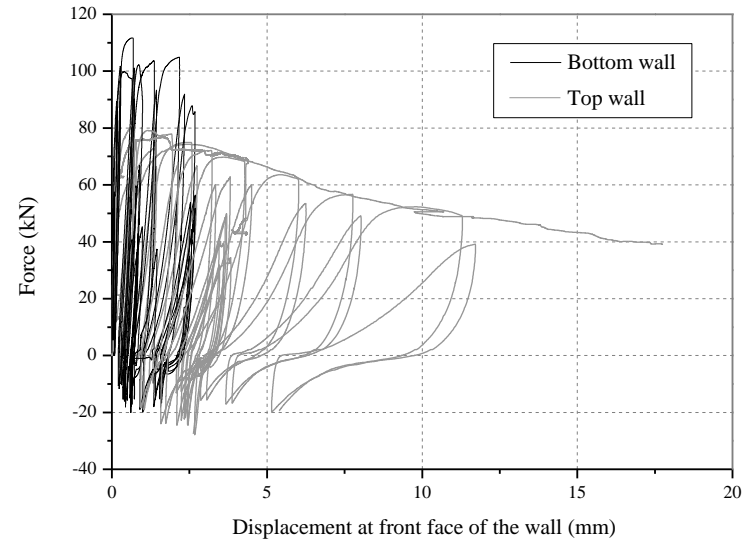

(a)

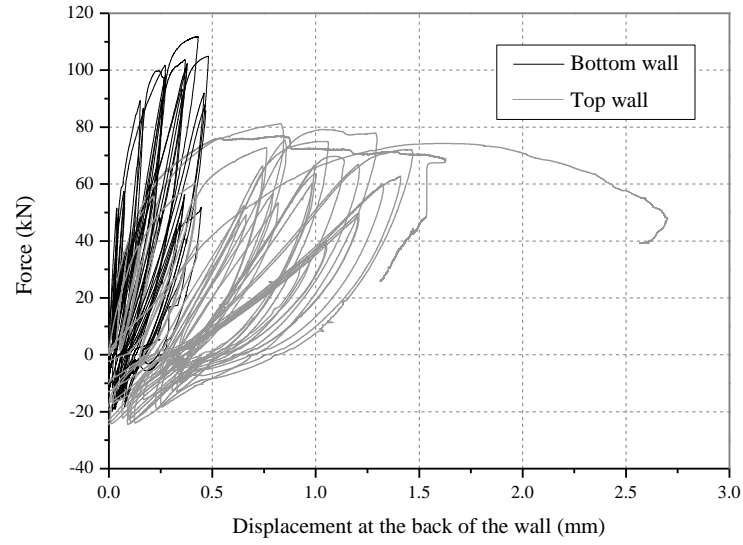

(b)

Fig. 13 Force-displacement curves of the wall: (a) front face of the wall; (b) back face of the wall. 


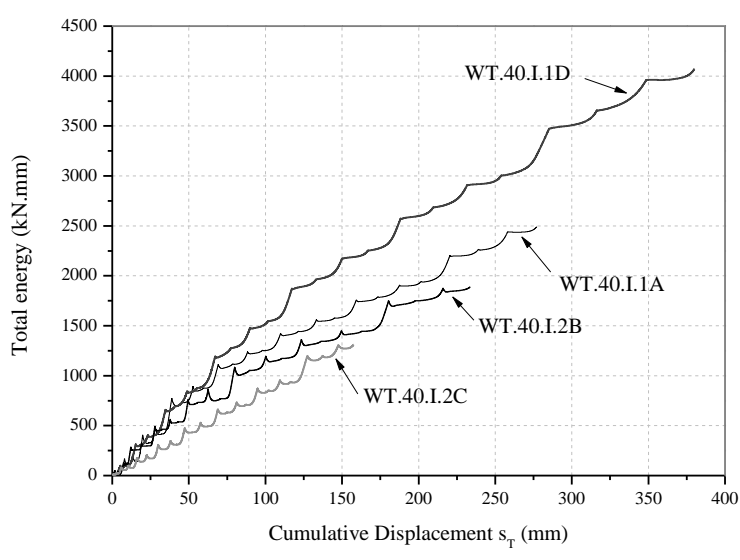

(a)

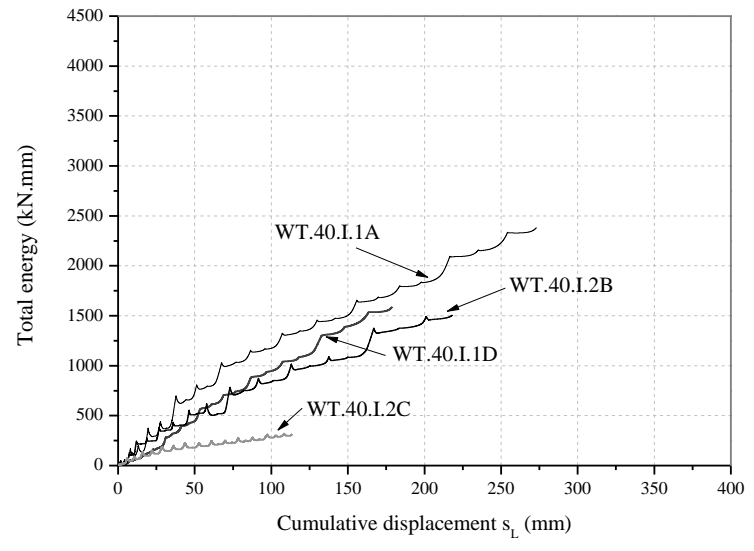

(b)

Fig. 14 Total energy analysis (a) based on $s_{T}$; (b) based on $s_{\mathrm{L}}$. 


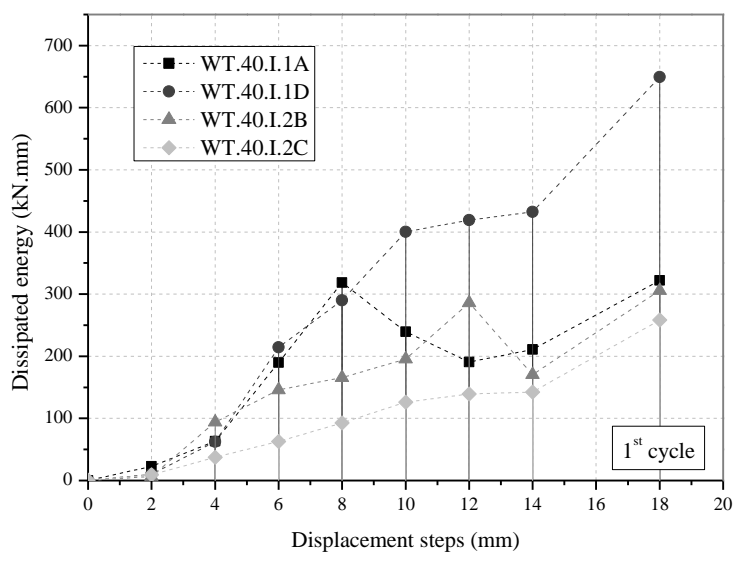

(a)

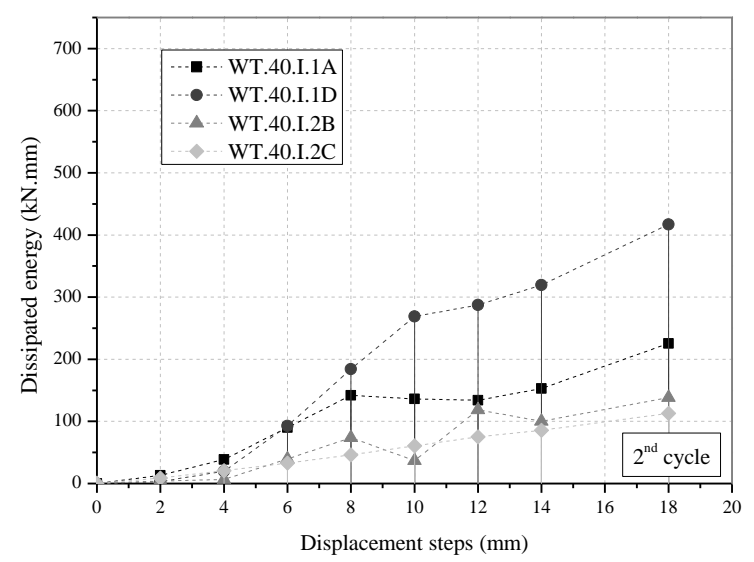

(b)

Fig. 15 Dissipated energy analysis per cycle: (a) $1^{\text {st }}$ cycle; (b) $2^{\text {nd }}$ cycle. 


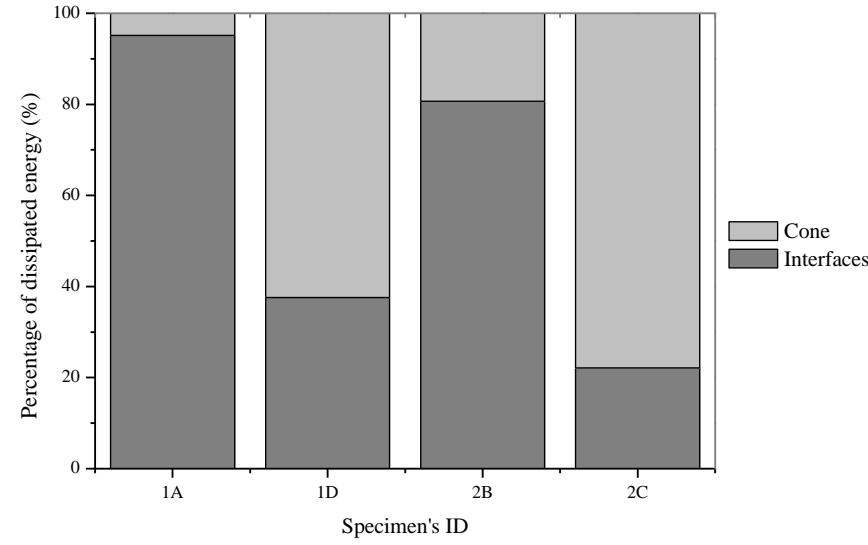

(a)

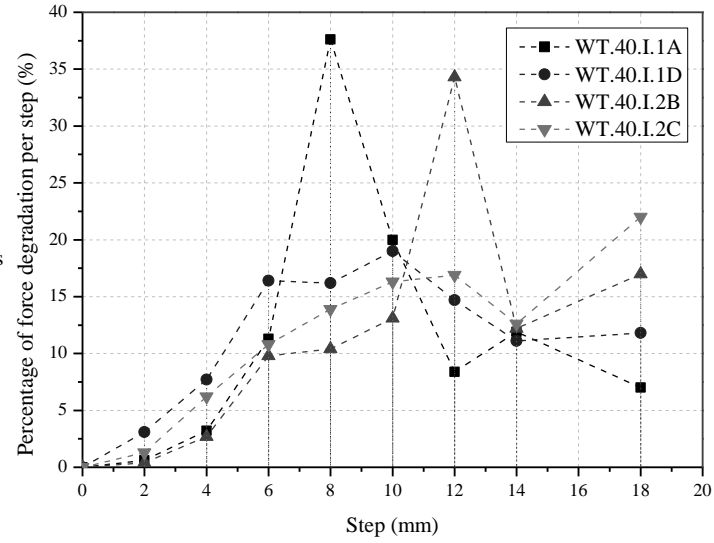

(b)

Fig. 16 (a) Energy dissipation per displacement contributions (interface and cone); (b) Percentage of force degradation between cycles per step. 


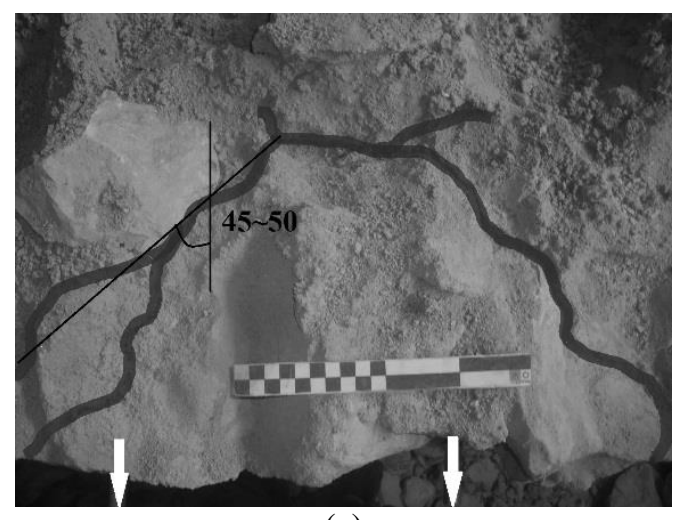

(a)

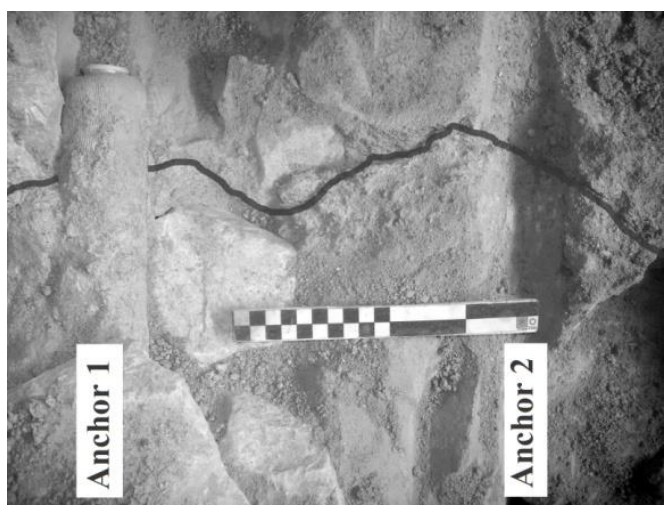

(b)

Fig. 17 Formation of the masonry cone: (a) top view of a fully formed cone; (b) cone intersecting the anchors 


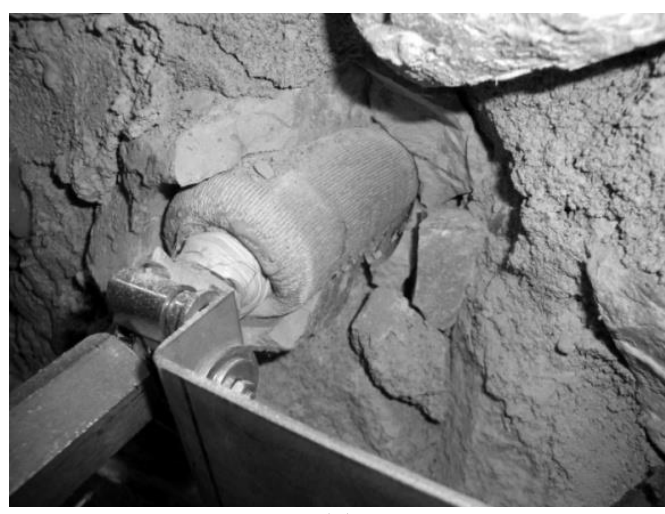

(a)

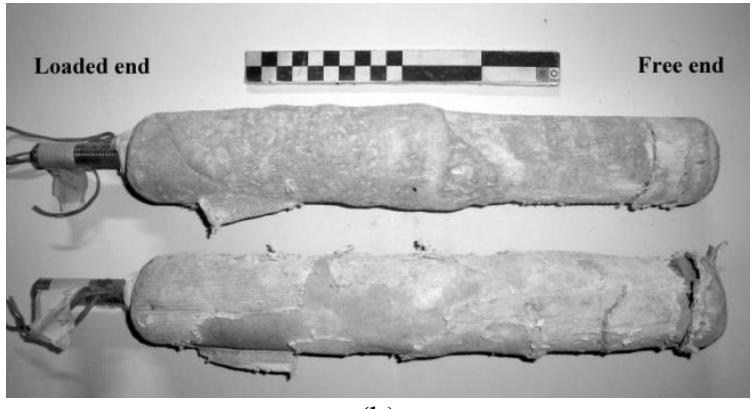

(b)

Fig. 18 Survey after testing: (a) sliding on the interface grout/masonry with detachment of a shallow masonry cone; (b) injection anchors after testing. 